DOI: 10.17805/trudy.2016.1.4

\title{
МОСКОВСКИЙ МЕТРОПОЛИТЕН КАК ФЕНОМЕН ГОРОДСКОЙ КУЛЬТУРЫ
}

\author{
М. С. Вальдес Одриосола \\ (Московский гуманитарный университет)
}

Аннотация: C статье предлагается применить для разработки новой конщепции Московского метрополитена в том числе культурологический подход.

Подготовлено на основе доклада на ХІІ Международной научной конференции «Высшее образование для ХХІ века» (3-5 декабря 2015 г.) в Московском гуманитарном университете.

Ключевые слова: Москва; метрополитен; Московский метрополитен; культурологический подход; тезаурусный подход; городская культура

\section{MOSCOW METRO AS A PHENOMENON OF CITY CULTURE}

\author{
M. S. Valdez Odriosola \\ (Moscow University for the Humanities)
}

Abstract: The article argues that the new concept of the Moscow Metro should, among other things, make use of the culturological approach.

The article is based on the paper given at the 12th International research conference "Higher education for the 21st century" (December 3-5, 2015) at Moscow University for the Humanities.

Keywords: Moscow; underground/subway; Moscow Metro; culturological approach; thesaurus approach; city culture

В связи с нестабильной ситуацией в мире в настоящее время поиск способов организации человеческой жизни, базирующейся на нравственных ценностях, является чрезвычайно актуальным. Прежде всего, это касается городского образа жизни, который оказался в проблемном поле еще в начале позапрошлого столетия, особенно же острота проблемы чувствуется сейчас, когда численность городского населения с каждым годом увеличивается. 
В решении данной проблемы немаловажную роль играют общественные пространства. Многие современные авторы уделяют особое внимание нравственным аспектам организации пространства жизнедеятельности человека (Назаров, 2014: 72). Однако пути решения проблемы часто разнятся. На наш взгляд, следует обращаться к опыту прошлого, в данном случае мы имеем в виду Московский метрополитен как общественнокультурную среду. В гармоничном сочетании красоты и функциональности станций первых линий московского метро не только заложены комфорт и эстетика, но и сформирована духовно-нравственная среда, к созданию которой так стремятся многие современные градостроители.

Создание Московского метрополитена как части пространства города-миллионера является результатом усилий исследователей и модернизаторов городских пространств, чья деятельность была направлена на решение многочисленных проблем функционирования больших городов. Поэтому для полноценного исследования московского метро в различных его аспектах необходимо рассмотреть, какие философские теории и социокультурные концепции послужили предпосылками к его появлению.

Практически на всем протяжении истории городских исследований середины XIX - середины XX вв. их корифеи отмечали проблему негативного влияния индустриальных городов на формирование личности (Энгельс, 1955: 263-264; Тённис, 2002: 9-131; Зиммель, 2002: Электр. ресурс; Парк, 2002). Они, в частности, писали о нравственных аспектах существования горожанина, его внутреннем мире. По мнению многих из них, в городской сутолоке и с ориентацией на ценности, базирующиеся на финансовой стратификации, житель большого города превратился в жестокого, бесчувственного, равнодушного, эмоционально выгоревшего, нервозного, обособленного, космополитичного индивида. Однако еще в конце XIX в. в Западной Европе появился кардинально новый подход к пониманию городского пространства, который позже лег в основу многих урбанистических исследований. Труд австрийского архитектора К. Зитте (1843-1903) «Художественные основы градостроительства» (1889) (Зитте, 1993) был посвящен влиянию архитектурно-художественного облика средневековых городов на формирование личности горожанина. Основное внимание в этой работе уделяется художественной культуре города как носительнице культурных норм и духовных ценностей.

Начало строительства Лондонского метрополитена стало поворотным моментом в истории городского общественного транспорта, кардинально изменившим городской образ жизни. Следует сказать, что во времена своего возникновения метро выглядело далеко не таким, каким мы его видим в настоящее время. Поначалу он не был полноценной ча- 
стью городского пространства (Misa, 1973). Демократичность первого в мире метрополитена (бесклассовые вагоны и низкая стоимость проезда) не искупала крайних неудобств. Первые вагоны были очень тесными и в них отсутствовали окна (Баннет, 2005: 22-23). Кроме того, они были наполнены клубами табачного дыма, отчего у многих пассажиров наступало предобморочное состояние (там же).

Таким образом, с первых лет существования метрополитена перед его создателями стояли серьезные задачи экологии человека. Несомненным прорывом в этом плане можно назвать несколько первых станций берлинского метро (U-Bahn). Своим обликом они обязаны тому, что во времена их постройки (1910-е гг.) германская архитектура находилась под влиянием идей австрийского архитектора К. Зитте (Зитте, 1993). Станции были сооружены в стиле вильгельминского периода, который также называют Северным Возрождением, и напоминают подземные дворцы, которые могли послужить источником вдохновения для архитекторов уже Московского метрополитена.

В настоящее время подземный транспорт многих мегаполисов переживает кризис, что с одной стороны, ставит под вопрос целесообразность его дальнейшего существования, а, с другой, заставляет искать пути решения накопившихся проблем из-за отсутствия альтернативы. В этом плане основной вид транспорта Москвы не стал исключением. Московский метрополитен чаще всего упоминается в контексте главных проблем города. Некогда самый красивый и самый удобный в мире метрополитен уже в течение нескольких десятилетий стал предметом постоянной критики как экспертов, так и пассажиров.

Для решения накопившихся проблем метро, остающегося важнейшим видом транспорта, необходимо провести целый комплекс исследований, культурологические в их числе.

Разрабатывая стратегию исследования культуры метрополитена в первую очередь необходимо определить, что и как исследовать в таком объекте, как метрополитен. На вопрос, как исследовать, отвечают появившиеся в последние десятилетия новые методы изучения культуры городского пространства. Среди них такие инновационные направления, как микроурбанизм, т. е. изучение города по его «деталям» и визуальная социология (визуальная антропология) (Бредникова, Запорожец, 2014; Штомпка, 2010; Магитов, Электр. ресурс). Вопрос же о том, что исследовать, гораздо сложнее.

Методология исследования архитектурного пространства города еще с начала XX в. разрабатывалась петербургским историком и краеведом Николаем Анциферовым (1889-1959). Он был первым в нашей стране, кто пытался раскрыть феномен городского образа жизни, рассматривая в 
комплексе разные его аспекты. Анциферов положил в основу своей концепции именно то, что можно в полной мере назвать психотипом города, несомненно оказывающим влияние на ментальность его обитателей (Анциферов, 1991: 33). На Западе подобными исследованиями занимались А. Лефевр и М. Фуко. На рубеже XX-XXI вв. под влиянием идей Лефевра, Фуко и др. сложились новые урбанистические школы: в Америке - лосанджелесская, а на европейском континенте - немецкая школа социологии архитектуры.

Однако при всей значимости работ по изучению социокультурного значения архитектурно-художественной составляющей городского пространства большинство вышеперечисленных исследований обходят стороной проблему изучения внутреннего мира горожанина, его личности, то, чего касался Анциферов в исследованиях художественной литературы, говоря о душевном состоянии ее героев, и без чего невозможно понимание поведения горожан, их образа жизни, проектирование и прогнозирование городской среды, а также преодоление деструктивных явлений городской жизни (Пирогов, 2004: 97). Эту проблему в определенной мере решают новые направления в городских исследованиях, в основу которых был положен феноменологический подход.

Философскую трактовку феноменологии культуры предложил Э. Гуссерль (1859-1938) на рубеже XIX-XX вв. (Гуссерль, 2010: 125-136). С позиций Баденской школы неокантианства Г. Риккерт (1863-1936) рассматривал феномены культуры, опираясь на постулаты аксиологии (Риккерт, 1912-1913). Позже австрийский социолог и философ А. Шюц (1899-1959), опираясь на учение Гуссерля, сформулировал концептуальные основания феноменологической социологии, поставив в центр исследования структуры повседневного мышления (Шюц, 1994: 485). Следующий шаг в понимании феноменов культуры сделали П. Бергер и Т. Лукман. В работе «Социальное конструирование реальности» (1966) (Бергер, Лукман, 1995) они рассматривают социальную реальность как комбинированную структуру. В основу своих исследований они положили утверждение о том, что человек - единственное живое существо, способное создавать «природу» вокруг себя, создавать культуру, тем самым конструируя реальность, а также рассматривали роль общества в ее создании (там же: 83).

Прикладные аспекты учения Бергмана и Лукмана о социальных конструкциях (универсумах) были разработаны рядом российских ученых (Вл. А. Луков, Вал. А. Луков, Н. В. Захаров, Ч. К. Ламажаа, А. В. Костина и др.), разработавших тезаурусный подход в гуманитарных исследованиях, где тезаурус определяется «как полный систематизированный свод освоенных социальным субъектом знаний» (Луков В., Луков Вл., 2008: 67). Авторы тезаурусного подхода акцентируют внимание на идее, согласно 
которой построение знаний в тезаурусе базируется на концептах, и на утверждении о том, что «особая структура сознания не равна понятиям: в концепте сливается логическое и образное, концепт выражает определенную ценность и эмоционально окрашен» (Луков, 2014: Электр. ресурс). Таким образом, понятие тезауруса сопрягается с утверждениями Зитте об архитектурных концепциях. Методологии тезаурусного подхода близко и утверждение, предложенное М. Вебером (1864-1920) о том, что в науках об обществе (или науках о культуре) поиск должен быть направлен (так же, как и у Риккерта) на определение значимого (ценного) для субъектов, т. е. их ценностных ориентиров (Гайденко, Давыдов, 1991: 40). Таким образом, «отнесение к ценности» характеризует не только степень актуальности исследования, но и актуальность самого исследуемого феномена в разные периоды его существования и развития путем соотнесения с «интересом эпохи» (Луков В., Луков Вл., 2014: 25).

«Отнесение к ценности» было конкретизировано академиком Д.С.Лихачёвым, рассматривавшим социокультурные аспекты представлений о ноосфере. Сформулировав понятие «экология культуры», он акцентировал свое внимание именно на проблеме духовно-нравственных ценностей (Лихачев, 2000: 91-102), представляющих особую актуальность для последующего развития человеческой цивилизации, носителями которых являются религии, а также художественная культура.

Кроме того, проводя культурологическое исследование Московского метрополитена, в первую очередь следует определить совокупность, а также актуальность тех духовно-нравственных ценностей, носителем которых некогда являлся этот вид транспорта, что включает в себя определение культурных констант, где последние представляют собой «долговременные центры притяжения в рамках определенной социокультурной реальности и одновременно фиксируют ее границы, позволяющие идентифицировать культурную систему, отделить ее от других» (Луков, 2008: 11).

\section{СПИСОК ЛИТЕРАТУРЫ}

Анциферов, Н. П. (1991) Непостижимый город. Л.: Лениздат. 335 с.

Афанасьев, К. (1950) Новые станции московского метро и их скульптурное убранство // Искусство. № 9-10. С. 7-8.

Беннет, Д. (2005) Метро. История подземных железных дорог. М. : Магма. 176 с.

Бергер, П., Лукман, Т. (1995) Социальное конструирование реальности. М.: Медиум. 324 с.

Бредникова, О., Запорожец, О. (2014) Микроурбанизм. Ловушка для города // Микроурбанизм. Город в деталях : сб. статей; под отв. ред. 
О.Бредниковой, О. Запорожец. М. : Новое литературное обозрение. 352 с. Бродский, Л. (1938) Освещение станций метро // Архитектура СССР. № 9. С. 11-17.

Гайденко, П. П., Давыдов, Ю. Н. (1991) История и рациональность: Социология Макса Вебера и веберовский ренессанс. М. : Политиздат. 367 с.

Гуссерль, Э. (2010) Идеи к чистой феноменологии и феноменологической философии. М. : Академический проект. 476 с.

Ермакова, Т. (1967) Первая очередь Московского метрополитена // Техническая эстетика. № 11. С. 18-22.

Зиммель, Г. (2002) Большие города и духовная жизнь [Электронный peсурс] // Логос. № 3-4. URL: http://magazines.russ.ru/logos/2002/3/zim. html (дата обращения 2.11.2015).

Зитте, К. (1993) Художественные основы градостроительства. М. : Стройиздат. 255 с.

Лихачев, Д. С. (2000) Русская культура. СПб. : Искусство - СПб. 400 с.

Луков, Вал. А. (2008) Молодежь и проблема культурных констант // Знание. Понимание. Умение. № 3. С. 11-17.

Луков, Вал. А. (2014) Ноосфера, понимаемая как тезаурус [Электронный ресурс] // Информационный гуманитарный портал «Знание. Понимание. Умение». № 2. URL: http://www.zpu-journal.ru/e-zpu/2014/2/Lukov_ Noosphere-Thesaurus/ (дата обращения 2.11.2015).

Луков, Вал. А., Луков, Вл. А. (2014) Методология тезаурусного подхода: стратегия понимания // Знание. Понимание. Умение. № 1. С. 18-35.

Луков, Вал. А., Луков, Вл. А. (2008) Тезаурусы: Субъектная организация гуманитарного знания. М. : Нац. ин-т бизнеса. 784 с.

Магидов, В. М. Визуальная антропология как социокультурное явление в ретроспективе и перспективе современного исторического знания [Электронный ресурс] // Московский дом национальностей. URL: http:// www.mdn.ru/cntnt/blocksleft/menu_left/nacionalny/pu-blikacii2/stati/v_m_ magido.html (дата обращения 2.11.2015).

Назаров, А. Г. (2014) Социальные аспекты безопасности атомной энергетики в контексте экологии культуры // Экологический ежегодник. С. 72-80.

Парк, Р. (2002) Город как социальная лаборатория // Социологическое обозрение. Т. 2. № 3. С. 3-12.

Пирогов, С. В. (2004) Феноменологическая социология и урбанистика // Вестник Томского государственного университета. № 282. С. 97-103.

Риккерт, Г. (1912-1913) Ценности жизни и культурные ценности // Международный ежегодник по философии культуры «Логос». Русское издание. М. : Мусагет. Кн. 1-2. С. 1-34.

Сосфенов, И. (1938) Проблема синтеза в метро // Искусство. № 6. С. 
64-65.

Тённис, Ф. (2002) Общность и общество: основные понятия чистой социологии. СПб. : Владимир Даль. 452 с.

Штомпка, П. (2010) Визуальная социология. М.: Логос . 168 с.

Шюц, А. (1994) Формирование понятия и теории в общественных науках// Американская социологическая мысль. М. : МГУ. 496 с.

Энгельс, Ф. (1955) Положение рабочего класса в Англии // Маркс К., Энгельс Ф. Сочинения. 2-е изд. М. : Госполитиздат. Т. 2. 651 с.

Misa T. (1973) The Compelling Tangle of Modernity and Technology // Misa T., Brey P., Feenberg A. (eds). People in places: The sociology of the familiar. N.Y.P. 208-216.

Дата поступления: 12.11.2015 2.

Вальдес Одриосола Мария Сантьяговна - аспирант кафедры философии, культурологи и политологии Московского гуманитарного университета, член Московского отделения ВТОО «Союз художников России». Адрес: 111395, Россия, г. Москва, ул. Юности, д. 5, корп. 3. Тел.: +7 (495) 374-60-21. Эл. адрес: odriosola@gmail.com

Valdez Odriosola Maria Santiagovna, postgraduate student, Department of Sociology, Moscow University for the Humanities; Member, Moscow Section, Union of Artists of Russia. Postal address: Bldg. 3, 5 Yunosti St., 111395 Moscow, Russian Federation. Tel.: +7 (495) 374-60-21. E-mail: odriosola@gmail.com 